aeroplanes when he ascended to $49,967 \mathrm{ft}$. According to The Times of September 30, Squadron Leader Swain was flying a low wing monoplane of wing span $66 \mathrm{ft}$. and length $44 \mathrm{ft}$. with a super-charged Pegasus engine designed to give 370 h.p. at the start, 457 h.p. at $40,000 \mathrm{ft}$. and 380 h.p. at 50,000 ft. The pilot was enclosed in an air-tight two-piece suit of fabric covered on both sides with rubber and surmounted by a helmet with a transparent window. His air supply was fed into the right side of the helmet and passed out on the left to a canister in which water vapour and carbon dioxide were removed before the air returned to the circulation. The cockpit of the aeroplane was also enclosed, and warmed from the engine exhaust. It appears that Squadron Leader Swain found no particular difficulty in the ascent, but when coming down, the window of his helmet and the cover of the cockpit were badly obscured by frost. He also experienced unpleasant sensations of suffocation accompanied by weakness, and was obliged to use his emergency knife to rip open his helmet. He landed safely after a flight lasting nearly three and a half hours. The height reached was nearly thirteen hundred feet above that attained last month by M. Georges Détré at Villacoublay, France.

\section{Crop-growing without Soil}

Artention has recently been given to production of green fodder for cattle and other farm stock without the intermediary of the soil. In Great Britain the method advocated is apparently of German origin, and it is claimed that the fodder is grown from seed in ten days. According to published accounts, a layer of seed (maize or other grain) is spread on a perforated metal tray, and the tray is placed in a cabinet, constructed to hold a series of trays. The seed is damped daily by water, containing a small percentage of nutrient salts, from a tank placed on the top of the cabinet, and, when an adequate temperature is maintained, the seed germinates and in 10 days a growth of shoots some 12 inches high is obtained. This growth of shoots, with the mass of rootlets, is then given to the stock. Several trials have shown that this fodder is readily eaten by stock, but carefully controlled. experiments are necessary to demonstrate the full nutritive value and the costs of production of this fodder. At the University of California experiments have been carried out by Prof. W. F. Gericke on the growing of vegetables and flowers in tanks of water to which the necessary chemical fertilizers have been added. The seeds are sown in a layer of sawdust or moss supported by wire netting above the water; the roots grow downwards and remarkably rapid growth and a high yield has been demonstrated. Although still in the experimental stage, this process has attracted the attention of commercial vegetable and flower growers in California.

\section{Huskless Oats}

During the past two years considerable public interest has been aroused in a variety of huskless oats introduced by Mr. William Parker of Babingley Hall, near King's Lynn. In 1936, with the agreement of the introducer, the National Institute of Agricultural Botany carried out accurate yield trials of this variety in Cambridgeshire, Somerset, Shropshire, Hampshire, Norfolk and Yorkshire. The rate of seeding (45 lb. per acre) and the sowing times (end of March and beginning of April) were those recom. mended by the introducer. The variety with which the oat was compared was Victory, and at each centre both were sown on the same day. Victory, however, was sown at the normal seed rate for that variety-3-4 bushels per acre. On the basis of grain as threshed, Victory outyielded Parker's Huskless oat by 97 per cent, but to obtain a true comparison 28 per cent must be deducted from the grain weights of Victory, this being the normal husk percentage of that variety. On this basis, at only one centroCambridge-did Parker's Huskless oat outyield Victory, and then by the insignificant amount of 2 per cent. Averaging the results from all six centres, taking both on the above basis of naked grain, the grain yield of Victory was $41 \cdot 2$ per cent heavier than Parker's Huskless oat. No shattering at harvest took place in either variety.

\section{Research and the Jute Industry}

A PARAgrapH under this heading appeared in NATURE of August 22 (p. 322), based on an article in Science and Culture discussing Dr. S. G. Barker's recommendations for research in the industry. Dr. Barker has written to point out that his report was on "Jute Research" as affecting jute manufacture, and should not be confused with the report of the Bengal Jute Enquiry Committee, which was concerned with agricultural aspects. His report was submitted to the Indian Jute Mills Association, which is at present considering it. Whether it will be submitted to the Government of India is a domestic matter for the jute manufacturers to decide. On the other hand, the suggestions of the Bengal Jute Enquiry Committee regarding jute agriculture have been accepted by the Government of India and a committee formed to implement them. So far as manufacturing research is concerned, this is still under sympathetic consideration by the Indian Jute Mills Assosiation.

\section{Social Life in a Rural Community}

A STUDY of the activities, interests and problems of young married men and women, 15-29 years of age, in the rural sections of Tompkins County, has been published by the Cornell University Agriculture Experiment Station, as part of a study of youth problems. The data were acquired by direct personal interview with each of the 347 persons included in the study. One third of the persons interviewed were men and two thirds were women. Of the whole group, 30 per cent lived on farms, 40 per cent in villages and 30 per cent lived in the open country but not on farms. On an average, these young people had spent more than two years at a high school, and two in five of the men and one in four of the women had received some college training. Only 4 per cent 